\title{
Panel of Psychological Inquiry: The Therapist's Perspective
}

\author{
STACY M. PODETZ ${ }^{\text {a,b }}$
}

a At the time of the Panel, graduate student in the Graduate program in Clinical Psychology, St. Michael's College, Colchester, VT

${ }^{\mathrm{b}}$ Correspondence concerning this article should be addressed to Stacy M. Podetz, PsyD Program in Clinical Psychology, Antioch University New England, 40 Avon Street, Keene, New Hampshire, 03431-3516. Email: spodetz@smcvt.edu

\begin{abstract}
I agreed to have my master's thesis case study with my client Anna" presented by a case advocate before a Panel of Psychological Inquiry, and to testify and be cross-examined before the Panel about my work. I will contrast my thesis defense on Anna's case study with appearing before the Panel, both in terms of my preparation and the myriad of emotions generated by this experience. My experience of the Psychological Inquiry was guided by my commitment to honor the confidentiality of Anna's story and our process together, while at the same time participating in a demonstration of a new methodology that might be used generally to examine $\mathrm{n}$ depth and to honor the work of clinicians.
\end{abstract}

Key words: self-injury, panic attacks, anxiety, eating disorder, depression, psychodynamic therapy, transference, counter-transference, defenses, case study, clinical case study

When I agreed to have my work presented before a Panel of Psychological Inquiry, I was excited to be part of a demonstration of new methodology. As my role in the demonstration was to have my master's thesis case study of Anna (Podetz, 2008, 2011) critiqued, I was in a vulnerable position. The intensity of my experience was magnified by the fact that Anna was my first client (and first case study) and by the fact that I was to be questioned and critiqued before (and by) a panel of highly distinguished judges. Despite these pressures, I was eager to be involved and my excitement outshone any apprehension that I had been feeling.

In accepting the opportunity to have my work presented to the Panel I had also hoped to illustrate the importance of case studies in the field. This importance became increasingly apparent to me during the process of writing the case, as my writing yielded invaluable insight and perspective on Anna's struggles. In fact, it was through the writing of the case that I began to recognize and understand the conflict that existed between Anna and her mother. I am not certain that this conflict would have been realized had I not approached the conceptualization of Anna's case through a case study methodology.

The weeks preceding the Panel of Psychological Inquiry came with very little anxiety, as I was too busy with the end of my masters degree and internship to fully acknowledge the magnitude of the experience. I decided, very strategically, to ignore the fact that I would be, 
along with my writing and work with Anna, critiqued and questioned. Instead I focused on the deadlines before me and I thrived on the energy that comes with fruition.

So, as I prepared for the Panel of Inquiry, I was also preparing for the termination of therapy with Anna. This was a very unique experience as the excitement of honoring our work together was coupled with the sadness of closure and goodbyes. The Inquiry was held the day prior to my last session with Anna and the significance was clear... the Inquiry was inextricably tied to my own closure with Anna. This realization was the clearest thought in my mind the morning of the Inquiry and the emotions attached to it were exhilarating and intense.

As I arrived at the Inquiry, I felt very confident with little nervousness. I had spent an enormous amount of time writing the case study and I had also spent one hour per week with Anna for the eight months prior. Because of this I knew, despite being outnumbered by the panel's hundreds of years experience, that I was the expert on this case. I believed in what happened in session with Anna and I approached the Inquiry with the purpose of honoring that and with the hope that the Panel would do the same.

\section{ADVOCATE CLAIMS AND AUTHOR'S TESTIMONY}

I had prepared in advance with the Case Advocate, Alexandra Altman, and was aware of the areas on which she planned to focus. Despite this, as she began to question me I remember feeling anxious and a little intimidated by the glare of the panel to the right of me. This surprised me but I quickly reminded myself that I was the most knowledgeable about this case and I became more comfortable. As I spoke more and more about the case of Anna, I became enthused and confident. I was mindful of my composure and was careful to maintain the focus on the facts of the case rather than the emotion attached to it. Even still, the emotion was evident.

I remember Alexandra choosing her questions and wording carefully as to be sure that I felt supported. In fact, for the entirety of the process, Alexandra maintained a constant consideration of my experience and of my feelings. In terms of the process of an inquiry and the role of the Advocate, I believe this type of nurturance, collegiality, and respect is imperative.

During the Inquiry, Alexandra made four claims about my case study. Firstly was that Anna presented with serious psychopathology. Secondly, that I provided Anna with humanistic and psychodynamically informed therapy. Thirdly, that a first year intern could provide effective therapy with a counseling center which was supported by Anna's growth. And finally, that Anna's cutting served a self-regulatory function as it offered relief to both numbness and tension. Alexandra substantiated these claims with my testimony, medical records, samples of Anna's creative writing, and with the testimony of Andrea Kelly (internship supervisor).

During cross-examination, Jess DiGiorgianni, the Case Critic, very skillfully attempted to find areas of uncertainty in my conceptualization and perception of the case in order to disprove the Advocate's claims. I was prepared for this and I also looked forward to it. I was excited to be challenged and I was prepared to be honest about any uncertainty. This was an important focus of mine throughout the Inquiry, as I wanted to illustrate the importance of an Inquiry to one's understanding of a case and as I wanted to broaden my own lens in order to serve Anna and other clients better in the future. 
Prior to the Inquiry, I imagined many emotions coming up... intrigue, anxiety, anger, satisfaction, pride, disappointment, curiosity, frustration, etc. In fact, throughout the course of the day each of these came up within myself and, although I had anticipated an array of emotions, I was fascinated by what the process evoked in me.

Specifically, while Jess DiGiorgianni was questioning me upon cross -examination, I felt frustrated because he suggested that Anna's cutting may have served functions other than being self-regulatory. This, although not mentioned in the advocate claims, was obvious to me and was clearly stated within the case study. In agreeing with the critic, it seemed to invalidate the advocate claim, which was broad for the purpose of a pilot Inquiry. This was only a minor frustration but it concerned me because I feared that Anna's story would be misunderstood. What is nice about the Inquiry process, however, is that I was given the freedom to clarify so that the Panel understood that I had always conceptualized Anna's cutting as serving many functions.

Throughout the rest of the cross-examination, I felt satisfaction, pride, and reassurance in the fact that Anna had grown and that I had played a part in that. I felt grateful for the opportunity to be part of the Inquiry and I felt validated as a beginning therapist.

\section{WITNESS TESTIMONY: ANDREA KELLY}

I felt the most frustration and anxiety as Jess DiGiorgianni questioned my internship supervisor, Andrea Kelly, who had been called as a witness to testify about the case of Anna. I was surprised by my discomfort during this portion of the Inquiry as I had thought I was prepared. However, it is very difficult to listen to others discuss and critique one's performance and almost impossible to do so quietly and without interrupting the speakers. It is apparent that the lack of control during this portion of the Inquiry was challenging, as I feared that my and Anna's voices would not be heard. I would caution that, in future Panel Inquiries, authors prepare themselves better for this and trust that the Panel's purpose is to find the client's voice rather than silence it. And, if the author was true to the client's voice, then she too will be validated.

\section{COUNTER-CLAIMS}

During the counter-claim portion of the Inquiry, I found myself more curious than defensive about the differing formulations of the case of Anna. I was confident that Anna had achieved therapeutic growth and that the therapy had been the catalyst for that, but what if I had missed something? I wanted to be critiqued and I wanted to be challenged for the sake of my growth as a therapist and for the sake of acknowledging the importance of a Psychological Inquiry. I remember smiling out of curiosity as Jess DiGiorgianni began to question me.

As the case critic questioned me, I felt determined, proud, and satisfied with the work I had done with Anna. I was intrigued by the case critic's suggestions of alternative ways of conceptualizing the case of Anna. Some of which I had taken into consideration and some of which I had not. Ultimately I knew that, as with all cases, there were many ways I could have approached and conceptualized it. There is always a level of uncertainly in this respect and there will always be "what ifs." I was interested to hear Jess' "what ifs" and I was receptive to them in the hopes of broadening my understanding. 
Jess posited that my combined humanistic and psychodynamic approach may have been counter-productive and he questioned how I moved forward when the two perspectives conflicted. I very honestly answered that the two did indeed conflict from time to time and that the way I approached such conflicts was with Anna's best therapeutic interest in mind and at heart. I used my best judgment, my clinical training, my theoretical training, and my intuition to decide how to best proceed and for the most part I think I got it right. However, there were times that I got it wrong and in these times the strength of the relationship, and a genuine apology, carried us through. Upon providing this answer I felt great pride in Anna and in myself and our process together. I was grateful for the opportunity to honor our work though the Psychological Inquiry.

In reflecting on my experience I realize that there is a definite frustration in being the author-therapist, because often we have a gut instinct and gut instincts do not necessarily hold up upon inquiry. Much of the time this work is such a slow process that, without knowing how exactly we arrived at a place of clarity, we must trust that we belong there. We must trust in the process. So when the critic asked about whether I considered that Anna's cutting was linked to self-disgust, I immediately answered that it wasn't, that instead Anna turned the hatred of others inward. It was then, and it was because of the Inquiry, that I had to revisit the path to this point of clarity. Although initially frustrating, this proved to be one of the more satisfying parts of the Inquiry because I was able to solidify, to the panel, to the critic, and to myself, that Anna felt no self-disgust and that I had conceptualized this correctly.

Jess DiGiorgianni also suggested a possible negative impact of my counter-transference on the therapy and directly quoted my case study text in order to corroborate this. While writing this case I had anticipated such criticism; however, I felt it necessary to be brutally honest about my own process with Anna. I was confident that I had monitored my counter-transferential reactions throughout the therapy and had worked very hard to maintain clarity and objectivity in the midst of them. I was also confident that, when I had failed to do so, I apologized and the relationship grew.

In substantiating his claim I remember Jess quoting the following passage from my case study (Podetz, 2008, p. 22) "For one moment of genuine emotion from Anna is worth the world to me and, I suspect, worth even more to her." As he read this to me, I felt pride and I knew that any negative impact that came from my counter-transference was minimal in comparison to the positive impact that came from it. The Panel could not know this... only Anna and I could... and I realized that this was enough for me.

In keeping with the spirit of the process of the Inquiry however, I concur with Jess that counter-transference can be negative and that, as it is unconscious, we may never acknowledge the full extent of it. All we can do, as good therapists, is to try our best to recognize discomfort and blocks and to constantly keep our client's therapeutic best interest in mind. I believe I did so with Anna.

\section{THE PANEL'S QUESTIONING}

I had anticipated tough questions from each member of the Panel and they did not disappoint me. I remember taking a deep breath as each question was asked and I did my best to 
answer with accuracy, clarity, and honesty. I appreciated each question asked of me as it provided me further insight and perspective and even validation. I answered each question thoughtfully and even recall asking for a few minutes to think as to be certain that my answer honored the therapy and the case study.

In retrospect, this may have been the most validating part of the entire Inquiry. Despite being in a vulnerable position, I maintained composure and confidence and I thrived on the excitement of proving to the Panel that my case study accurately depicted the work I had done with Anna and the growth she had experienced.

Close to the end of the Inquiry, one of the members of the Panel asked if I recognized my and Anna's parallel process. I had in fact, just days before, begun to recognize that both Anna and I were trying to find our way and define ourselves. We were both new at therapy. We both made mistakes and we both trusted the other to forgive and move forth in the midst of them. Most importantly, Anna and I both learned to trust in the process of therapy and of life.

Anna was my first client and will certainly hold a special place in my heart and life as our work together has helped to define me. As the sun went down that night and I prepared for closure with Anna the following day, the emotional impact of the Inquiry set in. Exhaustion, satisfaction, validation, and a sense of pride that what we had done together truly mattered.

\section{THESIS DEFENSE}

My master's thesis defense was about a month after the Panel of Psychological Inquiry. After having been asked every question I could imagine during the Inquiry I was not nervous about defending my thesis. However, after being given an entire day at The Inquiry to describe Anna's therapy, I found it very difficult to do so in the 90 minute period allotted for a thesis defense. This lack of time evoked the same fear as I had the day of the Inquiry... what if I could not honor Anna's growth and the work we had done?

The Panel of Psychological Inquiry gave me a sense of validation and allowed me a certain level of confidence in my ability that I had not had previously. I imagine this sort of validation, for others, is often the byproduct of a thesis defense. Although similar, I sense that the Panel of Psychological Inquiry creates more space for vulnerability, as one is being judged and critiqued by future professional colleagues in the field. On the other hand, a thesis defense also creates a certain level of anxiety because it is the culmination of years of hard work and can mean the difference between graduating and not graduating, as one is being critiqued by professors.

At a thesis defense (at least in the program I attended) there is a sense that one is innocent until proven guilty; however, during a Psychological Inquiry the opposite is true, one must prove their innocence. One must prove the merits of their case study and until he or she does, these merits remain unfounded. This fundamental difference encouraged in me a very different emotional reaction and intellectual approach. I entered the Inquiry with curiosity and a determination to prove myself. I entered my thesis defense with a sense of satisfaction, pride, and accomplishment. 
Testifying at the Panel of Psychological Inquiry gave me a sense of purpose and inspiration for the future while my thesis defense gave me a sense of pride in the past. Both were professionally enriching and inspiring and both were personally meaningful. Just as my work with Anna has, these experiences have also defined me as a therapist and will continue to have great significance in my life.

\section{THE VERDICT}

I think the Panel got it right. Although some of the criticisms were difficult to hear, I too had some of the same reservations they had expressed. Ultimately, Anna was my first client and my growth as a therapist paralleled her growth in therapy insofar as we both made gains and had setbacks.

Some criticisms and reservations noted within the Verdict, while valid, were frustrating as they were in fact concerns and criticisms clearly stated, through my own admission, in my case study. For example, one reservation was that the Anna's cutting was not only self-regulatory and that it likely had other functions. This fact was clearly stated within the case study; however, for the purpose of the pilot Inquiry, and of simplicity, we sought to support only one of the functions of Anna's cutting. Although it is tempting to become defensive when hearing such criticisms from the Panel, I perceive this as more of a structural fault of the Inquiry. As I see it, a remedy for this fault would be to more clearly state the claims so that such discrepancies are avoided. In addition, having such reservations raised by the Panel during the Inquiry would allow for the opportunity for clarification.

The criticisms about my counter-transference negatively impacting the therapy were the most difficult to hear as any therapist works to avoid just this and as I worked very hard to monitor it and avoid harm to Anna. My work with Anna was honest, as was my presentation at the Inquiry. I believe counter-transference has its place in therapy and I, to the best of my ability, monitored it to avoid harming Anna and, when appropriate, used it to benefit her. I will concur that there were likely times when my counter-transference hampered interpretations; however, I believe my emotion and attachment within the therapy was integral to Anna’s growth.

Throughout the entire process, I felt supported and I appreciated the collegial nature with which each participant approached the Inquiry. This, paired with the inquisitive nature of the Inquiry, was reminiscent of supervision, as we often look to others to help us see our biases and blocks and to validate our successes. Although difficult at times, the criticisms were necessary and meaningful and have served to make me a more knowledgeable and inquisitive therapist. Ultimately, as the author and as the therapist, this process was one of enlightenment and growth.

\section{REFERENCES}

Miller, R.B. (2011). Real Clinical Trials (RCT ${ }^{1}$ ) - Panels of Psychological Inquiry for transforming anecdotal data into clinical facts and validated judgments: Introduction to a pilot test with the case of “Anna.” Pragmatic Case Studies in Psychotherapy, 7(1), Article 2, 6-36. Available: http://hdl.rutgers.edu/1782.1/pcsp_journal 
Podetz, S. (2008) Seeing beyond the scars: A case study of “Anna.” Unpublished master's thesis in psychology. St. Michael's College: Colchester, Vermont.

Podetz, S. (2011). Seeing beyond the scars: A testament to “Anna.” Pragmatic Case Studies in Psychotherapy, 7(1), Article 3, 37-63. Available: http://hdl.rutgers.edu/1782.1/pcsp_journal

Note: After the Panel of Inquiry described in Miller (2011) was completed, Podetz's masters thesis was reformatted and copyedited to meet the guidelines of a PCSP case study, and some of the broader literature review was shortened. Aside from these two differences, the substance of Podetz's 2008 and 2011a versions of the case study of Anna are identical. 